\title{
POLÍTICAS PÚBLICAS PARA A EDUCAÇÃO NO BRASIL: DO TERCEIRO SETOR AO PROCESSO DE PRIVATIZAÇÃO DO ENSINO SUPERIOR
}

\author{
PUBLIC POLICIES FOR EDUCATION IN BRAZIL: FROM THE THIRD SECTOR TO \\ THE PRIVATIZATION PROCESS OF HIGHER EDUCATION
}

Patrícia Lakchmi Leite Mertzig Doutora em Educação - UEM Universidade Estadual de Londrina - UEL Londrina, Paraná, Brasil patriciamertzig@gmail.com

Camila Tecla Mortean Mendonça Mestre em Educação - UEM Universidade Cesumar - Unicesumar Maringá, Paraná - Brasil teclacamila@hotmail.com

\author{
Maria Luisa Furlan Costa \\ Doutora em Educação - UNESP/Araraquara \\ Professora no Programa de Pós-Graduação em Educação \\ Universidade Estadual de Maringá - UEM \\ Maringá, Paraná - Brasil. \\ luisafurlancosta@gmail.com
}

Resumo: Neste artigo, objetivamos refletir sobre a influência de organismos internacionais, como o Banco Mundial (BM), o Fundo Monetário Internacional (FMI) e a Organização das Nações Unidas para a Educação, a Ciência e a Cultura (UNESCO) nas políticas públicas para o Ensino Superior no Brasil. A adoção de políticas neoliberais teve início na década de 1990 e, desde então, estamos assistindo a uma série de mudanças que vão desde o incentivo e proliferação de Organizações não Governamentais (ONGs), enquanto terceiro setor, até aquelas que estão nos levando à privatização de todas as etapas da educação, de modo a chegar ao Ensino Superior. Por meio de uma abordagem bibliográfica e documental, o artigo realiza uma breve reflexão sobre o Plano Diretor da Reforma do Aparelho do Estado (BRASIL, 1995) e as recomendações do BM, FMI e da Unesco para a Educação. Autores como Netto e Braz (2010), Mészáros (2008), dentre outros, clarificam a influência de uma política pública baseada no ideário neoliberal para a Educação. Como exemplos, ponderamos sobre a Lei $\mathrm{n}^{\circ} 11.769$ de agosto de 2008, que versa sobre a obrigatoriedade do ensino de música nas escolas brasileiras e quanto à oferta desse ensino realizado por diversas ONGs. Observamos que, da mesma maneira, são semelhantes os discursos em prol da privatização do Ensino Superior que utilizam, inclusive, a Educação a Distância $(\mathrm{EaD})$. Concluímos que essas agências internacionais primam por manter vantagens ao mercado em detrimento de benefícios humanos, alterando, sobremaneira, as relações entre Estado, mercado e sociedade.

Palavras-chave: educação; ensino de música; ensino superior; neoliberalismo.

Abstract: In this article, we aim to reflect on the influence of international bodies, such as the World Bank (WB), the International Monetary Fund (IMF) and the United Nations Educational, Scientific and Cultural Organization (UNESCO) in public policies for Higher Education in Brazil. The adoption of neoliberal policies began in the 1990s and since then we are seeing a series of changes ranging from the encouragement and proliferation of non-governmental organizations (NGOs) as a third sector, to those that are leading us to the privatization of all stages of education, so as to reach higher education. Through a bibliographic and documentary approach, the article carries out a brief reflection on the Master Plan for the Reform of the State Apparatus (BRAZIL, 1995) and the recommendations of the World Bank, IMF and Unesco for Education. Authors such as Netto and Braz (2010), Mészáros (2008), among others, clarify the influence of a public policy based on neoliberal ideas for Education. As examples, we considered Law n ${ }^{\circ} 11,769$ of August 2008, which deals with the compulsory teaching of music in Brazilian schools and the offer of this teaching by several NGOs. We note that, in the same way, there are similar discourses in favor of the privatization of Higher Education that use, including, Distance Education $(\mathrm{EaD})$. We conclude that these international agencies tend to maintain advantages to the market to the detriment of human benefits, altering relations between state, market and society.

Keywords: education; higher education; neoliberalism; teaching music.

Para citar - (ABNT NBR 6023:2018)

MERTZIG, Patrícia Lakchmi Leite; MENDONÇA, Camila Tecla Mortean; COSTA, Maria Luisa Furlan. Políticas públicas para a educação no Brasil: do terceiro setor ao processo de privatização do ensino superior. Eccos - Revista Científica, São Paulo, n. 59, p. 1-18, e10781, out./dez. 2021. Disponível em: https://doi.org/10.5585/eccos.n59.10781. 


\section{Introdução}

A influência de organismos internacionais nas políticas públicas no Brasil se deu a partir da adoção do ideário neoliberal no fim da década de 1980 e início da década de 1990. O Brasil, nesse período, estava passando por uma grave crise que levou a economia a uma hiperinflação e, dessa maneira, foram propostas reformas para reorientar o desenvolvimento do país e redefinir o papel do Estado.

A eleição de Fernando Henrique Cardoso (FHC) à Presidência da República foi viabilizada a fim de que o país pudesse ser capaz de sustentar a permanência de programas de estabilização do Fundo Monetário Internacional (FMI) e tornar efetivas as reformas implementadas pelo Banco Mundial (BM). Destacamos, ainda, o Plano Real, concretizado em 1994, que se adequava às séries de medidas adotadas para a estabilização da moeda e o fim da hiperinflação.

Parte do pacote de medidas do plano de estabilização, não só para o Brasil, mas para o continente latino-americano, advinha de regras estabelecidas pelo Consenso de Washington formulado em 1989 (FIORI, 1997). A partir da observação da crise vivenciada pelos países da América Latina, com hiperinflações que chegaram a ultrapassar os 50\% mensais, como foi o caso da Bolívia (1985), do Peru (1988/1990), da Nicarágua (1988/1989), da Argentina (1989/1990) e do Brasil (1990), foi organizado um plano de ajuste econômico ao obter apoio das agências multilaterais, do tesouro nacional, do Ministério das Finanças, do Grupo dos Sete composto por Alemanha, Canadá, Estados Unidos, França, Itália, Japão e Reino Unido (G-7) e dos presidentes dos 20 principais bancos internacionais (BRESSER-PEREIRA, 1991).

De acordo com o Consenso de Washington, a crise Latino-americana tem duas causas: o tamanho do Estado e o protecionismo, ou seja, o excesso de empresas estatais e sua ineficiência, além da falta de capacidade de gerenciar a máquina pública e manter o controle salarial dos setores público e privado (BRESSER-PEREIRA, 1991). A fim de sair da crise que assolava o país e atender às exigências da política neoliberal, o Brasil inicia, em 1995, o Plano Diretor da Reforma do Aparelho do Estado.

Assim, foram articuladas ações governamentais, medidas legislativas e mudanças econômicas com o intuito de regular e reordenar o papel desempenhado pelo Estado, pois este, sob a nova ótica, deveria impulsionar a competitividade econômica. Para que isso se concretizasse, o governo FHC transformou o mercado em aliado, de modo a alterar a relação estabelecida entre Estado e sociedade e transferir, de forma rápida, o patrimônio público para o setor privado. 
As relações entre Estado e mercado se estreitam cada vez mais por meio de políticas públicas que favorecem a privatização de uma parte significativa dos serviços públicos. Isso significa que, gradativamente, as instituições privadas estão sendo financiadas com o dinheiro público para oferecer serviços à população. Nesse contexto, o discurso hegemônico inserido no ideário neoliberal nos faz acreditar que essa é a única saída para superar a crise que ainda se faz presente e que assola, principalmente, a educação de nosso país.

Esse é um dos motivos que gera constantes embates entre os setores público e o privado por meio de contínuas reformulações políticas que, cada vez mais, cedem ao mercado o controle de grande parte da educação de nosso país. Tal processo pode ser visto em todos os âmbitos sociais e, neste artigo, buscamos exemplificá-los por meio da apresentação de dois casos, partindo da principal característica neoliberal: a descentralização do papel do Estado.

No primeiro, ponderamos sobre a música e seu ensino. Tanto os documentos oficiais sobre a inserção da música na educação básica quanto a proliferação de ONGs responsáveis por disseminar o conhecimento musical nos permitem refletir sobre a influência do ideário neoliberal e das agências internacionais.

Para tanto, discorremos sobre o Plano Diretor da Reforma do Aparelho do Estado e o desenvolvimento do terceiro setor, por meio de ONGs que se responsabilizam por ensinar música corroborando o ideário neoliberal. Outra reflexão pertinente à área de música e de educação musical versa os quatro pilares da educação, texto apresentado por Jacques Delors, em 1998, e que faz parte do livro "Educação: um tesouro a descobrir (1998)" da UNESCO. Aqui, apresentaremos uma breve leitura dos Parâmetros Curriculares Nacionais (PCN) para o I ciclo do Ensino Fundamental e para o Ensino Médio, além do Referencial Curricular Nacional para a Educação Infantil (RCNEI) em relação ao conteúdo musical no intuito de verificar como os quatro pilares da educação estão inseridos nesses documentos. Observa-se, nesse sentido, a influência direta da UNESCO e do BM que, de alguma forma, apoiaram a aprovação da Lei ${ }^{\circ}$ 11.769 de 2008, que versa sobre a obrigatoriedade do conteúdo de música nas escolas brasileiras.

Em seguida, nossa discussão se encaminha para a questão da privatização dos serviços públicos. Nessa seção, iremos nos debruçar em problematizar a legislação que tem permitido que a Educação seja ofertada pela iniciativa privada. De acordo com dados do MEC, a nossa Educação Básica é a mais privatizada do mundo e, apesar disso, as políticas públicas continuam a seguir no rumo da privatização dos demais níveis de ensino. Nesse âmago, focalizamos o Ensino Superior e a oferta da Educação a Distância $(\mathrm{EaD})$, tendo em vista as recomendações do Banco Mundial para esse nível educacional. 


\section{A música na educação básica e o papel das ONGs na oferta do ensino de música}

O Plano Diretor da Reforma do Aparelho do Estado foi desenvolvido pelo Ministério da Administração Federal e da Reforma do Estado (MARE) que, após muitos debates e discussões, acabou aprovado em 21 de setembro de 1995 pela Câmara da Reforma do Estado, sendo sancionado, posteriormente, pela Presidência da República. Esse documento "define objetivos e estabelece diretrizes para a reforma da administração pública brasileira, instrumento indispensável para consolidar a estabilização e assegurar o crescimento sustentado da economia” (BRASIL, 1995, p. 6). De acordo com Santos (2011, p. 62):

[...] a administração gerencial adotada pelo governo teve como finalidade reduzir custos e tornar mais eficiente a administração das imensas tarefas que cabem ao Estado. A reforma apresenta as seguintes características: descentralização, delegação de autoridade e de responsabilidade ao gestor público e extremo controle de desempenho. Esta forma de administrar é voltada para obtenção de resultados.

A reforma do Estado brasileiro foi um processo abrangente que buscava "criar um novo modelo econômico fundamentado no neoliberalismo", sendo pautado por regras estabelecidas no Consenso de Washington (1989). De acordo com os defensores da Reforma, essa seria "uma alternativa capaz de liberar a economia para uma nova etapa do crescimento" (CARINHATO, 2008, p. 41).

Como pode ser observado, o Plano Diretor é um documento que recomenda a reforma administrativa do Aparelho do Estado e, nele, é possível observar, de forma expressa e objetiva, que o que se propõe é uma redefinição do papel do Estado. Logo, na apresentação do próprio documento, lemos: "Este 'Plano Diretor' procura criar condições para a reconstrução da administração pública em bases modernas e racionais” (BRASIL, 1995, p. 6).

No documento, o cidadão é tratado como cliente e a administração pública deve ser gerenciada, além de ter como foco a qualidade do produto por meio de um controle eficiente. Ou seja, intenciona-se liberar o aparelho do Estado das amarras burocráticas que atrapalham o desenvolvimento geral da nação, características estas de governos anteriores. O que se pretende com essa proposta é acelerar o crescimento do Brasil com pouca intervenção do Estado na economia e passando o mercado a ser o regulador do crescimento e prosperidade nacionais.

Assim, o Estado vê nas privatizações uma forma mais eficiente de gerenciar a produção e comercialização de produtos, tornando-os mais competitivos e esperar que o próprio mercado, por meio da livre concorrência, mantenha a qualidade necessária. 
Desse modo o Estado reduz seu papel de executor ou prestador direto de serviços, mantendo-se entretanto no papel de regulador e provedor ou promotor destes, principalmente dos serviços sociais como educação e saúde, que são essenciais para o desenvolvimento, na medida em que envolvem investimentos em capital humano; para a democracia, na medida em que promovem cidadãos; e para uma distribuição de renda mais justa, que o mercado é incapaz de garantir, dada a oferta muito superior à demanda de mão-de-obra não-especializada (BRASIL, 1995, p. 13).

O Estado minimiza sua ação para ser apenas regulador e argumenta que a pouca intervenção agilizaria o progresso econômico, pois evitaria toda uma burocracia que gira em tordo da comercialização em relação a produtos e serviços em nome da suposta eficiência que só o mercado é capaz de oferecer. De acordo com Lara e Silva (2008, p. 115-116):

Percebe-se que o Estado se autodenomina como apenas um promotor dos serviços sociais que mantêm o controle social direto com a participação da sociedade, ou seja, estimulando outros setores por meio da "publicização" - a descentralização para o setor público não - estatal da execução de serviços que não envolvem o exercício do poder de Estado, mas devem ser subsidiados pelo Estado, como dos serviços de educação, saúde, cultura e pesquisa científica.

Dessa forma, a música, enquanto produção artística e cultural, fica reduzida à ação de ONGs, autarquias e empresas privadas. O que pode ser observado, atualmente, é que não só a música, mas também todas as outras formas de expressão artísticas, como teatro, dança, dentre outras, ficam sob responsabilidade de empresas que apoiam os projetos sociais que utilizam a arte para colaborar com o Estado de bem-estar social. O Estado, nessa etapa, entraria como catalizador e facilitador nessas ações, e não mais é responsável por fomentar a cultura nacional.

Colocar a cultura nas mãos da iniciativa privada por meio de ONGs é justamente uma característica de políticas guiadas pelo ideário neoliberal. Ou seja, o desenvolvimento cultural de um povo não é mais obrigação dos organismos que o regem; ficam, contudo, sob responsabilidade do chamado terceiro setor. Na acepção de Gohn (apud ROMERO; NOMA, 2008, p. 91):

[...] o terceiro setor é uma expressão com significados múltiplos devido a sentidos históricos diferenciados, em termos de realidades sociais". Trata-se, portanto, "[...] de uma nova ordem social, que se coloca ao lado do Estado - o primeiro setor e do mercado - tido como o segundo setor.

A cultura e a arte, que são elementos essenciais a uma nação, ficam a cargo da boa vontade de empresários em mantê-las ativas e isso, atualmente no Brasil, acorre mais intensamente nas grandes capitais. Em relação à ideologia neoliberal, Netto e Braz (2010, p. 226, grifos dos autores) nos esclarece da seguinte maneira: 
O que se pode denominar por ideologia neoliberal compreende uma concepção de homem (considerando atomisticamente como possessivo, competitivo e calculista), uma concepção de sociedade (tomada como um agrado fortuito, meio de o indivíduo realizar seus propósitos privados) fundada na ideia da natural e necessária desigualdade entre os homens e uma noção rasteira de liberdade (vista como função da liberdade de mercado).

Essa "natural e necessária desigualdade entre os homens" citada é, justamente, o que permeia as ações ligadas às produções artísticas e culturais. Cobrar pelo ingresso em salas de concerto, teatro e outros tipos de espetáculo contribui para que o acesso à cultura seja restrito àqueles que podem pagar para usufruir de obras primas criadas por e para seres humanos. A fragmentação da sociedade é concretizada com espaços que não serão usufruídos por todos. São experiências estéticas restritas a um grupo social, mesmo que esses grupos não tenham, necessariamente, compreensão para absorvê-las e interpretá-las. Ainda assim, adentram nesse universo cultural, porque têm condições financeiras de ali ingressarem.

A assimilação artística envolve experiências e conhecimentos em arte em todas as suas modalidades, como a música, a pintura, a escultura, a fotografia, o circo, o teatro, a dança, o cinema e tantas outras formas de expressão humana e que deveriam ser acessíveis a todos os cidadãos. Esse conhecimento envolve metodologias e conteúdos próprios que só podem ser ensinados e aprendidos nos bancos escolares. Portanto, a disciplina Arte é um importante conteúdo escolar, mas não deve ficar restrito ao espaço escolar. É preciso acrescentar atividades extracurriculares, como visitas a museus, teatros e outros espaços na condição de ações formativas igualmente essenciais.

No que se refere ao Estado de bem-estar social, que equivale a ações voltadas a um estrato da população em situação miserável, vemos, no campo cultural, projetos promovidos por ONGs que utilizam a música como um atrativo a essa população carente de ocupar seu tempo com atividades culturais. Inúmeras são as circunstâncias quando observamos projetos movidos, por exemplo, pelo "Criança Esperança", da Rede Globo de Comunicação e em parceria com a UNESCO.

Essas ações são formas elucidativas de notarmos como o ideário neoliberal age colocando nas mãos da população (a população que doa dinheiro ao Criança Esperança, por exemplo) a obrigação de contribuir com projetos assistenciais, de modo a tirar esse "peso" do Estado, como se ele não tivesse a obrigação de manter a cultura, além de outros segmentos, como a saúde, o transporte, a moradia etc.

Dessa maneira, é possível relacionar a música e a cultura, de forma geral, por meio de três facetas: aquela apresentada como obra prima, realizada por profissionais e financiada por empresas privadas e consumidas por aqueles que têm melhores condições financeiras; aquela 
que está presente nos projetos sociais como uma forma de dar acesso à cultura para um estrato da população mais carente, como ações de bem-estar social e mantidas pela iniciativa privada; e, por fim, a música, que deveria ser ensinada nas escolas e que pode se tornar uma importante forma de discussão e transformação social ao ampliar o acesso à cultura, de modo universal, para uma camada maior da população. Essa última também é custeada pela iniciativa privada, ainda que não em sua totalidade.

Destarte, temos uma ausência do Estado como responsável pela formação musical da população e que cerceia o acesso à cultura. É nesse panorama de um ideário neoliberal, todavia, que as atividades que envolvem esse setor se configuram. Para ultrapassar esse cenário, é preciso que a educação, enquanto direito humano, seja concebida e balizada por leis que não sofrem ações diretas do mercado, porém isso não é o que ocorre. De acordo com Mészáros (2008, p. 25):

[...] uma reformulação significativa da educação é inconcebível sem a correspondente transformação do quadro social no qual as práticas educacionais da sociedade devem cumprir as suas vitais e historicamente importantes funções de mudança.

Concernente ao exposto, o que vemos são órgãos internacionais interessados em manter o mercado como regulador social e que, por meio do BM, da UNESCO e do FMI, tomaram, para si, a responsabilidade de definir ações no campo educativo em países como o Brasil.

O BM não apresenta ideias isoladas mas uma proposta articulada - uma ideologia e um pacote de medidas - para melhorar o acesso, a equidade e a qualidade dos sistemas escolares, particularmente do ensino de primeiro grau nos países em desenvolvimento. Embora se reconheça que cada país e cada situação concreta requerem especificidade, trata-se de fato de um "pacote" de reforma proposto aos países em desenvolvimento que abrange um amplo conjunto de aspectos vinculados à educação, das macropolíticas até a sala de aula (TORRES, 2003, p. 126).

O BM e a UNESCO são, atualmente, agências que organizam encontros, promovem debates, apresentam documentos a temas ligados à Educação em nível mundial. Em 2011, por exemplo, o BM, com base em paradigmas que regem o ideário neoliberal, apresenta o relatório Estratégia 2020 para a educação, em que “[...] prossegue discutindo em favor de um maior papel para si na governança global, assim como defendendo um papel expandido para o setor privado de desenvolvimento" (ROBERTSON, 2012, p. 284).

Por sua vez, a UNESCO apresentou, em 1998, o chamado Relatório da Comissão Internacional sobre Educação para o Século XXI, coordenado por Jacques Delors. Esse relatório foi publicado em 1999 como livro, cujo título é: "Educação: um tesouro a descobrir"; ademais, o relatório é apresentado na íntegra ao incluir, no quarto capítulo, a discussão acerca dos quatro pilares da educação. 
De acordo com o relatório, a educação deve oferecer aos estudantes condições de saber e saber-fazer, ou seja, são competências e habilidades que o educando deve desenvolver, de forma a pensar e agir com mais criticidade em relação às inúmeras informações disponíveis e incentivar que a busca pelo conhecimento não termine no período escolar, mas tenha continuidade ao longo da vida.

\begin{abstract}
Para poder dar resposta ao conjunto das suas missões, a educação deve organizar-se em torno de quatro aprendizagens fundamentais que, ao longo de toda a vida, serão de algum modo para cada indivíduo, os pilares do conhecimento: aprender a conhecer, isto é adquirir os instrumentos da compreensão; aprender a fazer, para poder agir sobre o meio envolvente; aprender a viver juntos, a fim de participar e cooperar com os outros em todas as atividades humanas; finalmente aprender a ser, via essencial que integra as três precedentes. É claro que estas quatro vias do saber constituem apenas uma, dado que existem entre elas múltiplos pontos de contato, de relacionamento e de permuta (UNESCO, MEC, 1998, p. 89-90, grifos do documento).
\end{abstract}

A questão, agora, é verificar como esses quatro pilares que norteiam as ações educacionais aparecem nos documentos oficiais brasileiros desenvolvidos pelo MEC e apresentados aos professores para atuarem na Educação Básica. Esses documentos são, por exemplo, os Parâmetros Curriculares Nacionais, as Diretrizes Curriculares Nacionais, o Conselho Nacional de Educação, dentre outros, como a própria Lei de Diretrizes e Bases para a Educação. Como esses documentos são específicos para cada disciplina escolar e divididos de acordo com a idade dos alunos (Educação Infantil, $1^{\circ}$ e $2^{\circ}$ ciclos do Ensino Fundamental e Ensino Médio), vamos nos ater, ainda que de forma breve, ao RCNI e aos PCN do $1^{\circ}$ ciclo do Ensino Fundamental e do Ensino Médio, ao se ocuparem do ensino da música.

O Referencial Curricular Nacional para a Educação Infantil (BRASIL, 1998), em seu terceiro volume denominado Conhecimento de Mundo, dedica, aproximadamente, 45 páginas para tratar do ensino musical. Nelas, são apresentados conteúdos e metodologias que o professor da educação infantil pode abordar em suas aulas. Na introdução do capítulo, o texto aponta para a deficiência na formação do professor e que, em relação à música, adota práticas mais imitativas do que criativas e expressivas. Há, no texto, a valorização de atividades de criação, pois o ensino de música, assim como o ensino de artes, de forma geral, é pautado no tripé: produção-apreciação-reflexão. Em relação aos quatro pilares da educação propostos pelo relatório da UNESCO, vemos que a música desenvolve, muito eficazmente, o que foi proposto no relatório: "A linguagem musical é excelente meio para o desenvolvimento da expressão, do equilíbrio, da auto-estima e autoconhecimento, além de poderoso meio de integração social" (BRASIL, 1998, p. 49). 
Nos Parâmetros Curriculares Nacionais de Arte para o $1^{\circ}$ ciclo do ensino fundamental, a Arte é entendida como área e, em sua introdução, o texto aponta para a arte como produção humana universal e coloca a experiência artística em primeiro plano. No trecho a seguir, é possível perceber, também, o discurso do relatório quando solicita participação ativa dentro e fora da sala de aula. O "aprender a conhecer" e "aprender a fazer" são presentes no discurso desse documento.

\begin{abstract}
Para que a aprendizagem da música possa ser fundamental na formação de cidadãos é necessário que todos tenham a oportunidade de participar ativamente como ouvintes, intérpretes, compositores e improvisadores, dentro e fora da sala de aula. Envolvendo pessoas de fora no enriquecimento do ensino e promovendo interação com os grupos musicais e artísticos das localidades, a escola pode contribuir para que os alunos se tornem ouvintes sensíveis, amadores talentosos ou músicos profissionais. Incentivando a participação em shows, festivais, concertos, eventos da cultura popular e outras manifestações musicais, ela pode proporcionar condições para uma apreciação rica e ampla onde o aluno aprenda a valorizar os momentos importantes em que a música se inscreve no tempo e na história (BRASIL, 1997, p. 54).
\end{abstract}

Adiante, averiguamos que, nos Parâmetros Curriculares Nacionais para o Ensino Médio (2000), a Arte se enquadra no segundo livro chamado Linguagens, Códigos e suas tecnologias. No sumário, os capítulos são apresentados como competências e habilidades e a Arte ocupa o $4^{\circ}$ lugar, sendo antecedida pelo conhecimento em Língua Portuguesa, Língua Estrangeira Moderna e Educação Física.

No capítulo introdutório do conhecimento em Arte, o texto reconhece que a área sofre descaso em relação às outras áreas de conhecimento, mas contextualiza, historicamente, os movimentos dos arte-educadores para colocar a área como importante no processo formativo em nível escolar. O discurso referente aos quatro pilares também não se altera muito em relação aos outros documentos já apresentados.

Para que a aprendizagem da música possa ser fundamental na formação de cidadãos
é necessário que todos tenham a oportunidade de participar ativamente como ouvintes,
intérpretes, compositores e improvisadores, dentro e fora da sala de aula. Envolvendo
pessoas de fora no enriquecimento do ensino e promovendo interação com os grupos
musicais e artísticos das localidades, a escola pode contribuir para que os alunos se
tornem ouvintes sensíveis, amadores talentosos ou músicos profissionais.
Incentivando a participação em shows, festivais, concertos, eventos da cultura popular
e outras manifestações musicais, ela pode proporcionar condições para uma
apreciação rica e ampla onde o aluno aprenda a valorizar os momentos importantes
em que a música se inscreve no tempo e na história (BRASIL, 2000, p. 49).

Os três exemplos apresentados estão de acordo com a Lei n ${ }^{\circ}$ 9.394/1996, que separou o conhecimento em Arte a partir de suas modalidades artísticas, como a música, o teatro, a dança e as artes visuais. Como todos esses exemplos são anteriores à Lei no 11.769 de 2008, mas compreendendo que essa Lei é uma alteração da Lei de 1996, percebemos que os discursos dos EccoS-Rev. Cient., São Paulo, n. 59, p. 1-18, e10781, out./dez. 2021 
organismos internacionais estão bastante presentes quando abordamos, especificamente, o ensino de música na escola. A nova Lei só vem assegurar a música como ensino obrigatório e abordá-la, de acordo com os documentos oficiais, para garantir o que foi descrito no relatório organizado por Jacques Delors.

Ainda que esteja fora do escopo deste estudo, registramos documentos, como a Base Nacional Comum Curricular (BNCC), a qual, para o ensino de Arte na educação básica, apresenta-se como um retrocesso à área. O texto, em sua última versão, valoriza mais as competências e os objetivos se destacam de forma diluída. Segundo Peres (2017, p. 30-31):

\begin{abstract}
A Arte como um componente dentro da Área de Linguagem corre o risco de se tornar apenas uma disciplina acessória que ajudará a compreender determinado conteúdo de Língua Portuguesa ou de Literatura, acarretando na negligência de seus conteúdos próprios 31 que ajudam na reflexão e na crítica de objetos artístico-culturais situados em diversos tempos históricos e em diferentes contextos culturais. No texto da BNCC, as Linguagens Artísticas (Artes Visuais, Dança, Música e Teatro) são consideradas como subcomponentes do componente Arte, dando margem para interpretações equivocadas e para o retorno da famigerada polivalência, tendo como justificativa a necessidade da valorização do trabalho interdisciplinar.
\end{abstract}

Assim, fecha-se o ciclo da participação direta da iniciativa privada no âmbito cultural, pois, de um lado, a escola deve ensinar conteúdos artísticos e incentivar os alunos a participarem, ainda que como espectadores, da produção cultural nacional que a mesma iniciativa privada mantém. Uma ação que justifica e mantém a outra; com isso, o Estado intervém apenas como regulador e incentivador dessas ações. É nesse sentido que a Lei $\mathrm{n}^{\circ}$ 11.769/2008, que obriga o ensino de música nas escolas, pode ser compreendida.

\title{
3 Privatização da educação: as recomendações do banco mundial para o ensino superior público
}

Todas as mudanças que vêm sendo articuladas desde a década de 1990 caminham para a privatização do Ensino Superior no país. Conforme exposto nas discussões até aqui, o Decreto $n^{\circ}$ 9.057/2017 permite, ainda mais, a participação das instituições privadas na oferta do Ensino Superior, assim como incentiva a sua expansão, como aponta os dados do Censo da Educação Superior na modalidade a distância, publicados em setembro de 2018, mas referentes ao ano de 2017. 
Tabela 1 - Número de ingresso em cursos de graduação, por categoria administrativa - 2007 a 2017

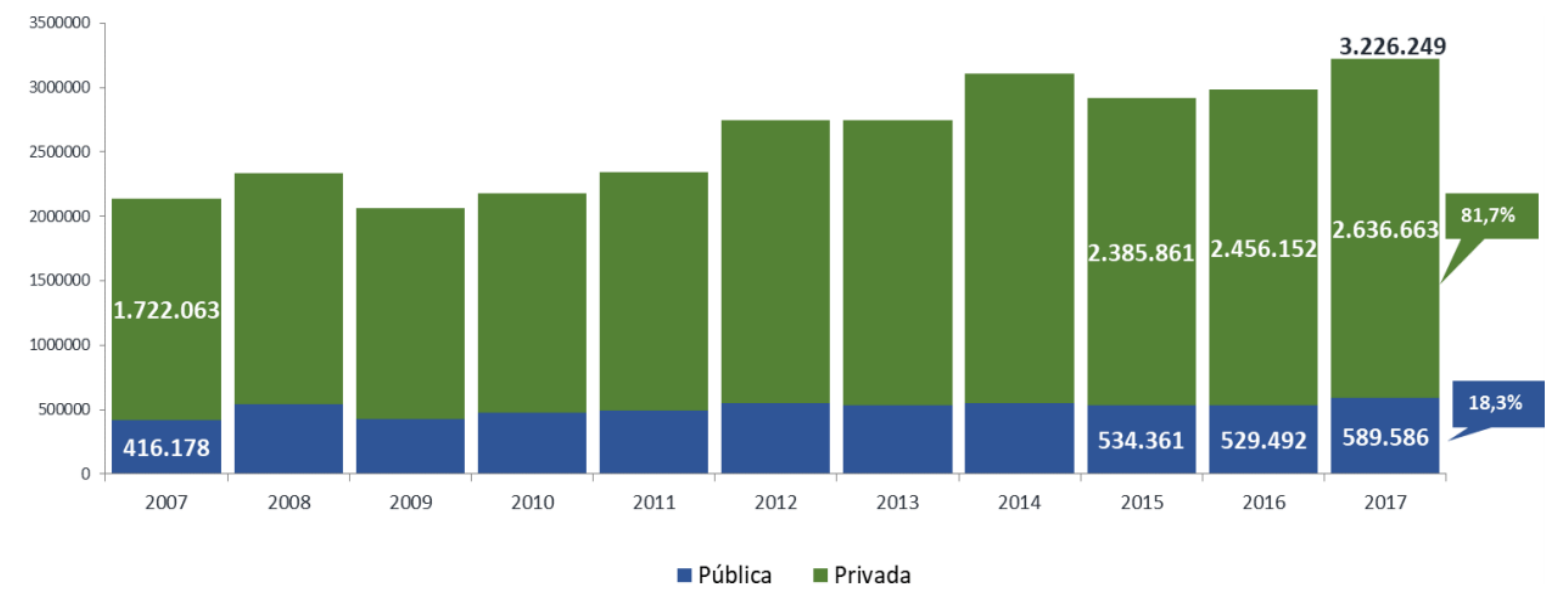

Fonte: BRASIL, 2018.

Ao analisar os dados publicados pelo MEC, percebemos que, em comparação ao ano de 2007, no ano de 2017, tivemos a matrícula de mais de 3.200.000 de alunos no Ensino Superior. Destes, mais de 2.600 .00 estão nas instituições privadas, o que representa $81,7 \%$ do total. Nesse contexto, podemos afirmar que a rede privada de Educação Superior continua em crescimento, representando um aumento de 8,1\% nas matrículas em relação ao ano de 2016, mas, em comparação aos anos de 2007 e 2017, a iniciativa privada obteve um crescimento de 53,1\%.

Cabe nessa análise ainda, justificando em números a expansão do Ensino Superior na rede privada, a comparação entre as modalidades de ensino, conforme a Tabela 2 a seguir.

Tabela 2 - Número de ingresso em cursos de graduação, por modalidade de ensino - 2007 a 2017

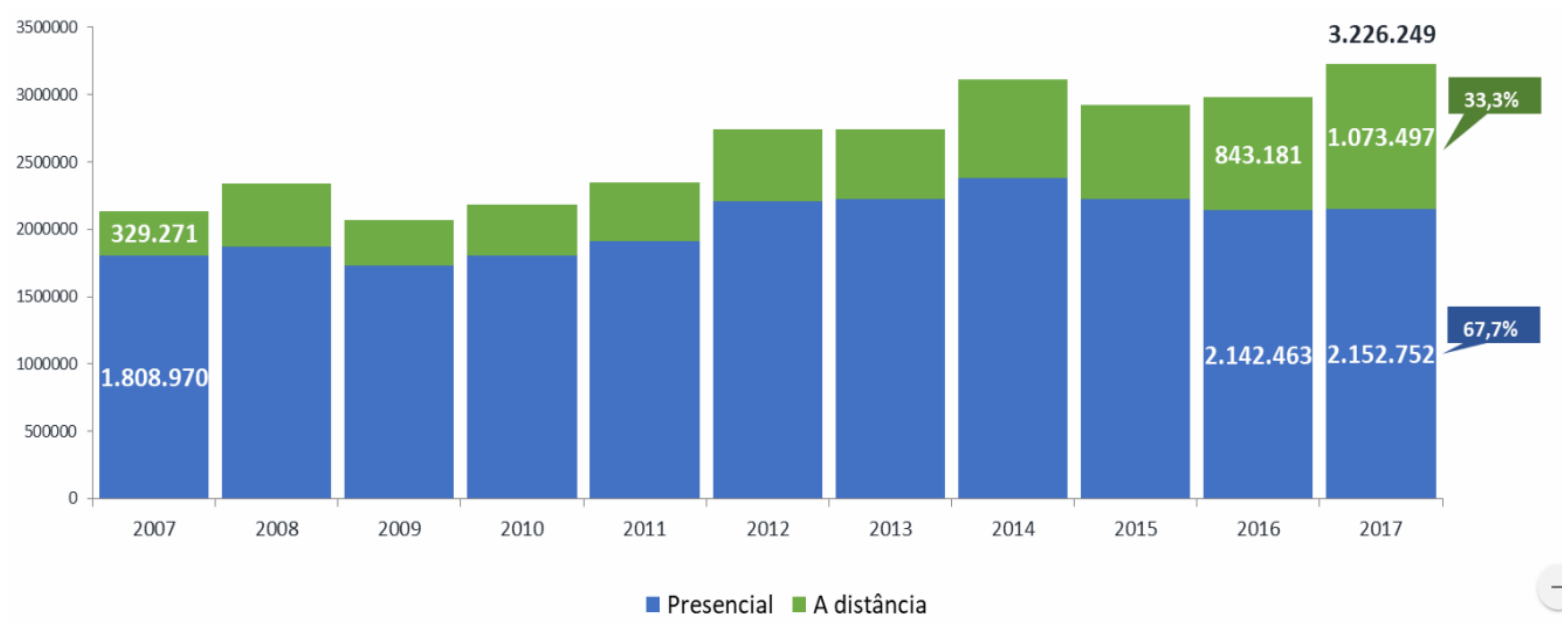

Fonte: BRASIL, 2018. 
Ao verificar as informações da Tabela 2, podemos perceber que a EaD foi responsável por 1/3 do ingresso dos alunos nos cursos de graduação na Educação Superior. Conferindo os números de 2007 e 2017, o quantitativo de ingressos variou nas duas modalidades de ensino. No ensino presencial, por exemplo, a variação foi de $19 \%$ e, na modalidade a distância, a variação foi de $226 \%$.

Acreditamos que a permissividade que encontramos na legislação faça parte do pacote que cede, cada vez mais ao setor privado, a oferta dos serviços que são de responsabilidade do Estado, levando o consenso público ao discurso da ineficiência das universidades públicas e a necessidade de sua privatização.

Desde 1995, o BM vem formulando recomendações para os países em desenvolvimento, de modo a prestar assistência técnica e financeira; dentre esses países, salienta-se o Brasil, o qual, desde as últimas décadas, enfrenta uma crise no Ensino Superior. De acordo com Borges (2010, p. 369), o Banco Mundial tem recomendado reformas na Educação Superior no que se refere à: "diferenciação institucional; diversificação das fontes de financiamento; redefinição do papel do Estado e as questões referentes à autonomia e à responsabilidade institucional e políticas voltadas para a qualidade e equidade". Prossegue a autora:

Na redefinição da função do governo, o Banco mundial recomenda que o Estado não
se abstenha de promover a educação superior, mas orienta que essa promoção se
concentre em: políticas voltadas para o estabelecimento de um marco regulatório
coerente, em que o governo assuma o papel de supervisor do sistema; incentivar
mecanismos orientados para o mercado na aplicação das políticas, tais como
disponibilizar informações, visando fortalecer a qualidade da educação e mecanismos
de certificação da qualidade; promover uma maior autonomia administrativa das
instituições públicas, de maneira que possam diversificar suas fontes de financiamento
e utilizar, de forma mais eficiente, os seus recursos; avaliar o desempenho das
instituições públicas e privadas de educação superior (BORGES, 2010, p. 369).

Podemos perceber que o foco maior nessa redefinição do papel do Estado está em administrar as políticas e regular a oferta do Ensino Superior, e não, de fato, oferecê-la. O papel do Estado se dissolve em relação à oferta da Educação Superior, pois esse nível de ensino não é prioridade para o desenvolvimento econômico do país, de acordo com a política neoliberal. Nesse quadro, o Estado é visto como ineficiente e com gastos exacerbados.

A partir da necessidade de controlar as contas públicas e tornar o Estado mais eficiente, o governo brasileiro, no ano de 2017, encomendou ao BM um relatório, com o objetivo de analisar os gastos públicos e a eficiência da gestão do Estado, assim como apontar alternativas para torná-lo mais sustentável e reduzir o déficit fiscal, uma ação que recebe o título de $U m$ ajuste justo: análise da eficiência e equidade do gasto público no Brasil (BANCO MUNDIAL, 2017). 
O documento elaborado de forma "neutra" pelo BM também contou com a participação de membros do governo em exercício. Destacamos os seguintes pontos nesse documento:

1. O Brasil possui mais gastos do que receita e não sabe aplicar os seus recursos;

2. por gastar mais do que arrecada, o Brasil está colocando em risco a sua saúde fiscal;

3. O ajuste dos gastos públicos irá minimizar os impactos aos mais pobres e vulneráveis, assim como os empregos e o atendimento dos serviços públicos;

4. O ajuste, em longo prazo, no que se refere à economia fiscal, seria possível por meio da reforma da previdência;

5. O relatório recomenda o pagamento de mensalidades nas universidades públicas.

Em breve análise do documento, podemos identificar que o relatório não tem características técnicas, ao contrário do que é declarado. As propostas indicadas também sinalizam que os programas beneficiariam os estratos mais ricos da sociedade, em detrimento dos mais pobres, além da grande propensão em não atingir seus objetivos. Nas reformas expostas para aumentar a eficiência e a equidade da Educação Superior, bem como reduzir seus gastos, o documento aponta para a diminuição de gasto por aluno, indicando às universidades com menos recursos a busca de meios em outras fontes.

Uma opção para aumentar os recursos das universidades federais sem sobrecarregar
o orçamento seria a introdução de tarifas escolares. Isso é justificável, pois o ensino
superior oferece altos retornos individuais aos estudantes e, com base em dados atuais,
o acesso privilegia fortemente estudantes de famílias mais ricas. Paralelamente, é
necessário facilitar o acesso a mecanismos de financiamento para estudantes que não
possam pagar as mensalidades. Felizmente, o Brasil já possui o programa FIES, que
oferece empréstimos estudantis para viabilizar o acesso a universidades privadas. O
mesmo sistema deveria ser expandido para financiar o acesso a universidades federais.
A ampliação do FIES para incluir universidades federais poderia ser combinada ao
fornecimento de bolsas de estudos gratuitas para os estudantes dos $40 \%$ mais pobres
da população, por meio do programa PROUNI. Juntas, essas medidas melhorariam a
equidade do sistema e gerariam uma economia para o orçamento federal de
aproximadamente $0,5 \%$ do PIB (BANCO MUNDIAL, 2017, p. 138).

Existem críticas em relação ao documento, tendo em vista que as recomendações do BM já se mostraram ineficientes em outros países, acirrando, ainda mais, suas crises econômicas. O que precisamos é de um governo que se preocupe com a população brasileira, principalmente com as classes pobres e que invista no desenvolvimento do país e em educação pública e de qualidade. Da forma como o documento citado sugere, além de criar mensalidades para as universidades públicas federais, o estrato mais pobre da população terá de se contentar 
em estudar em Instituições de Ensino Superior (IES) privadas, cuja característica principal é a qualidade questionável dos processos formativos, além de manter a segregação estudantil.

Em relação à $\mathrm{EaD}$, os decretos que regulamentam a oferta da Educação Superior na modalidade contribuem com o processo de privatização das IES, uma vez que há incentivo para que a iniciativa privada ofereça esse nível de ensino. Os fomentos são realizados por meio de recebimento de repasse de verbas em plataformas sociais, como o Programa Universidade para Todos (PROUNI) e Fundo de Financiamento Estudantil (FIES), já mencionados no documento. Compete ao Estado somente a realização da regulamentação, fiscalização e avaliação das instituições e dos cursos, aferindo, assim, a qualidade do ensino ofertado.

Apesar da expansão da Educação Superior e sua comercialização se efetivar em grande parte pode meio da $\mathrm{EaD}$, não podemos conceber a modalidade, somente pelo ideário neoliberal, como uma mercadoria que é vendida para satisfazer os anseios da formação de mão de obra para o mercado de trabalho. A EaD foi implementada no Brasil como uma estratégia para a democratização do acesso à educação pública de qualidade, mas idealizá-la de forma diferente não condiz com as lutas e a trajetória histórica que essa modalidade de ensino tem enfrentado para que, de fato, tenhamos uma educação pública de qualidade para todos (MENDONÇA, 2016).

É importante salientar, também, que a EaD estreitou as barreiras que impediam o acesso de uma grande parte da população à educação e à educação continuada, pois foi por meio dessa última que pessoas residentes de todas as partes do Brasil, das mais remotas, que nunca tiveram oportunidade de acesso à Educação Superior, encontraram uma alternativa viável aos estudos. A EaD tem tornado o sonho do curso superior uma realidade, formando milhares de profissionais todos os anos (MENDONÇA, 2016).

Nesse contexto, a EaD está possibilitando a formação em nível superior a milhares de pessoas que, se não fossem por essa modalidade de ensino, nunca teriam acesso, contribuindo, dessa forma, para a democratização do ingresso à Educação Superior, especialmente para as camadas mais populares da sociedade. Assim, em um país de dimensões continentais, como é o Brasil, que apresenta contrastes culturais e sociais relevantes, a EaD tem se consolidado como uma possibilidade real de democratização de acesso ao Ensino Superior (MENDONÇA, 2016).

\section{Considerações finais}

Por intermédio das reflexões abordadas no decorrer deste texto, buscamos caracterizar não somente a reforma do Estado brasileiro, mas também articulá-la com as recomendações 
educacionais estabelecidas pelos organismos internacionais. Como observado, a reforma do Estado foi fortemente influenciada e conduzida pelas agências internacionais que, por meio das diretrizes estabelecidas nas conferências, nos fóruns e nos seminários, definiram-se as estratégias que seriam adotadas para a implantação das medidas estipuladas, implicando uma grande redução dos investimentos públicos em políticas para a população de baixa renda, o que ocasionou a subordinação do país à política econômica do BM.

Para tanto, as ações descritas nos documentos das agências internacionais, além de pontuarem a favor da privatização dos níveis educacionais, visam à construção e à viabilização de projetos que favorecem o setor privado, de maneira a contribuir para a mercantilização da educação.

Podemos concluir que o BM, mesmo adotando uma postura que viabiliza recursos para os países em desenvolvimento, de forma que estes possam ser investidos em infraestrutura, educação, políticas sociais, está vinculado a projetos comprometidos com a manutenção da nova visão de mundo e legitimada pela burguesia conservadora brasileira. Diante disso, os métodos que são empregados para que as diferenças sociais sejam amenizadas estão amarrados aos conceitos de eficiência, rentabilidade e produtividade.

Nesse pacote, está a Educação Superior, também na modalidade a distância, que tem se apresentado como objeto mercantil do Ensino Superior, pois os decretos que regulamentam essa modalidade favorecem, cada dia mais, as instituições privadas. Desse modo, as ações implementadas por essa política mudaram a forma como o Brasil passou a ser administrado e influenciaram, de maneira profunda, as relações entre Estado, mercado e sociedade.

Outro exemplo dessa ação versa sobre a música na educação básica, bem como as leis que a regulamentam. Quando observamos que mudanças ocorrem também porque são movidas por agências internacionais, como o BM e a UNESCO, e compreendemos o real interesse dessas agências que primam por manter vantagens ao mercado em detrimento de benefícios humanos, vemos que as artes e, mais especificamente, a música, não passam de elementos necessários à manutenção dessa nova ordem mundial. Obrigar a música como conteúdo escolar é proporcionar ao educando uma forma de ter contato com elementos culturais, saber valorizálos e ter conhecimento para se expressar por meio da música. Isso, indubitavelmente, é necessário e importante. Observamos, contudo, que a produção artística e a manutenção da cultura se mantêm no âmbito da iniciativa privada, enquanto deveriam ser de responsabilidade do Estado.

Nesse sentido, o conhecimento em arte aprendido na escola fica subordinado ao mercado e este não mantém somente o controle sobre a produção artística, mas é responsável 
pela distribuição da arte entre as pessoas. Por esse motivo, o acesso às obras primas se torna, muitas vezes, restrito não só pelo custo do ingresso, como também pela distância que a arte tem da vida da maioria da população.

Dessa forma, a escola é considerada o único meio de ingresso à cultura para uma quantidade significativa da população. Por outro lado, sabemos que muitos estudantes acessam às obras de arte por iniciativa familiar, e não escolar. Eles se apresentam na escola com uma maior vantagem de aprendizagem em relação aos demais alunos. Esse aspecto que percebemos nas escolas brasileiras atuais é, justamente, um aspecto abordado por Pierre Bourdieu (1998). Quando o autor nos apresenta sua teoria do capital cultural, vemos que alguns estudantes têm, e outros não.

A cultura "livre", condição implícita do êxito em certas carreiras escolares, é muito desigualmente repartida entre os estudantes universitários originários das diferentes classes sociais e, a fartiori, entre os de liceus ou os de colégios, pois as desigualdades de seleção e a ação homogeneizante da escola não fizeram senão reduzir as diferenças. O privilégio cultural torna-se patente quando se trata da familiaridade com obras de arte, a qual só pode advir da frequência regular ao teatro, ou museu ou a concertos [...]. Em todos os domínios da cultura, teatro, música, pintura, jazz, cinema, os conhecimentos dos estudantes são tão mais ricos e extensos quanto mais elevada é sua origem social (BOURDIEU, 1998, p. 45).

A escola, nessa esfera, deve cuidar para não destacar as diferenças sociais tão fáceis de serem cometidas, principalmente nas aulas em que são abordados conteúdos em arte. Nesse contexto, depreendemos que o campo em que a educação brasileira se encontra visa à manutenção de uma política neoliberal e de um Estado mínimo, delegando às ONGs e à iniciativa privada a oferta dos serviços que são de sua responsabilidade.

Acreditamos na educação como uma forma de emancipação dos sujeitos; logo, priválos de ter acesso a esse conhecimento, seja pela ausência de conteúdos, seja pela falta de políticas de manutenção à educação pública, é um retrocesso quanto aos direitos garantidos na Constituição Federal a todos os cidadãos.

\section{Referências}

BANCO MUNDIAL. Um ajuste justo: análise da eficiência e equidade do gasto público no Brasil. Volume I: síntese. Novembro, 2017.

BORGES, Maria Creuza de Araújo. A visão de educação superior do Banco Mundial: recomendações para a formulação de políticas educativas na América Latina. RBPAE, Brasília, v. 26, n. 2, p. 367-375, 2010.

BOURDIEU, Pierre. Escritos de educação. In: NOGUEIRA, Maria Alice; CATANI, Afrânio (org.). Petrópolis: Vozes, 1998. 
BRASIL. Decreto $n^{\circ}$ 9.057, de 25 de maio de 2017. Regulamenta o art. 80 da Lei $n^{\circ} 9.394$, de 20 de dezembro de 1996, que estabelece as diretrizes e bases da educação nacional. Brasília, DF: Presidência da República, 2017. Disponível em:

http://www. planalto.gov.br/ccivil_03/_ato2015-2018/2017/decreto/D9057.htm. Acesso em: 20 nov. 2021.

BRASIL. Lei $n^{o}$. 9.394, de 20 de dezembro de 1996. Estabelece as diretrizes e bases da educação nacional. Brasília, DF: Presidência da República, [2009]. Disponível em: http://www.planalto.gov.br/ccivil_03/leis/19394.htm. Acesso em: 20 nov. 2021.

BRASIL. Lei $n^{\circ} 11.769$, de 18 de agosto de 2008. Altera a Lei ${ }^{\circ} 9.394$, de 20 de dezembro de 1996, Lei de Diretrizes e Bases da Educação, para dispor sobre a obrigatoriedade do ensino da música na educação básica. Brasília, DF: Presidência da República, 2008. Disponível em: http://www.planalto.gov.br/ccivil_03/_Ato2007-2010/2008/Lei/L11769.htm. Acesso em: 20 nov. 2021.

BRASIL. Ministério da Educação e do Desporto. Referencial Curricular Nacional para a Educação Infantil. Brasília, DF: MEC/SEF, 1998.

BRASIL. Ministério da Educação e do Desporto. Parâmetros Curriculares Nacionais para o Ensino Médio. Linguagens, códigos e suas tecnologias. Brasília, DF: MEC/SEF, 2000.

BRASIL. Ministério da Fazenda. Censo Demográfico 2017. Resultados gerais da amostra. IBGE. Brasília, DF: Secretaria de Política Econômica, 2018. Disponível em: http://portal.inep.gov.br/web/guest/sinopses-estatisticas-da-educacao-superior. Acesso em: 20 nov. 2021.

BRASIL. Ministério do Planejamento. Plano Diretor da Reforma do Aparelho do Estado. Brasília, DF: MP, 1995. Disponível em: http://www.planejamento.gov.br/ editoria.asp?p=editoria\&index=25\&ler=t524. Acesso em: 20 nov. 2021.

BRASIL. Secretaria de Educação Fundamental. Parâmetros Curriculares Nacionais: arte. Brasília, DF: MEC/SEF, 1997.

BRESSER-PEREIRA, Luiz Carlos. A crise da América Latina: consenso de Washington ou crise fiscal? Pesquisa e Planejamento Econômico, Rio de Janeiro, v. 21, n. 1, p. 5-22, 1991.

CARINHATO, Pedro Henrique. Neoliberalismo, reforma do estado e políticas sociais nas últimas décadas do século XX no Brasil. Revista Aurora, Marília, v. 2, n. 3, p. 37-49, 2008.

FIORI, José Luís. Ajustes e milagres latino-americanos. In: FIORI, José Luís. Os Moedeiros Falsos. Petrópolis: Vozes, 1997. p. 47-59.

LARA, Angela Mara de Barros; SILVA, Jani Alves da. Políticas públicas para a educação infantil no Brasil: qualidade, descentralização e focalização. In: AZEVEDO, Mário Luiz Neves de (org.). Políticas Públicas: debates contemporâneos e educação. Maringá: Eduem, 2008. p. 107-137. 
MENDONÇA, Camila Tecla Mortean. O Estado do conhecimento na educação superior a distância e a intervenção dos organismos internacionais nas políticas públicas (2001 a 2014). 2016. 137 f. Dissertação (Mestrado em Educação) - Universidade Estadual de Maringá, Maringá, 2016.

MÉSZÁROS, István. A educação para além do capital. Tradução: Isa Tavares. 2. ed. São Paulo: Boitempo, 2008.

NETTO, José Paulo; BRAZ, Marcelo. Economia política: uma introdução crítica. 6. ed. São Paulo: Cortez, 2010.

PERES, José Roberto Pereira. Questões atuais do Ensino de Arte no Brasil: o lugar da Arte na Base Nacional Comum Curricular. Revista de Educação, Desenho e Artes Visuais do Colégio Pedro II, Rio de Janeiro, v. 1, n. 1, p. 24-36, 2017.

ROBERTSON, Susan Lee. A estranha não morte da privatização neoliberal na Estratégia 2020 para a educação do Banco Mundial. Revista Brasileira de Educação, [S. I.], v. 17, n. 50, p. 283-302, 2012.

ROMERO, Ana Paula Hamerski; NOMA, Amélia Kimiko. "Novos" movimentos da sociedade civil, no final do século XX: o terceiro setor na educação. In: AZEVEDO, Mário Luiz Neves de (org.). Políticas Públicas: debates contemporâneos e educação. Maringá: Eduem, 2008. p. 81-105.

SANTOS, Ademar Sousa dos. A reforma administrativa do Estado brasileiro nos anos 90 e a proposta de descentralização educacional. Práxis Educacional, Vitória da Conquista, v. 7, n. 11, p. 53-72, 2011.

TORRES, Rosa Maria. Melhorar a qualidade da educação básica? As estratégias do Banco Mundial. In: TOMMASI, Lívia; WARDE, Mirian Jorge; HADDAD, Sérgio (org.). O Banco mundial e as políticas educacionais. 4. ed. São Paulo: Cortez, 2003. p. 125-193.

UNESCO/MEC. Educação, um tesouro a descobrir. São Paulo: Cortez; Brasília, DF: MEC/UNESCO, 1998. 